\title{
EXTRAÇÃO E CARACTERIZAÇÃO DE AMIDO DE JACATUPÉ (Pachyrhizus ahipa) ${ }^{1}$
}

\author{
Magali LEONEL ${ }^{2, *}$, Silene B. S. SARMENTO ${ }^{3}$, Marney P. CEREDA ${ }^{4}$, Francisco L.A.CÃMARA ${ }^{5}$
}

\begin{abstract}
RESUMO
O gênero Pachyrhizus tem sido estudado como fonte de matéria-prima amilácea devido ao considerável teor de amido nas raízes de suas espécies. Neste trabalho objetivou-se caracterizar raizes de $P$. ahipa, processar em laboratório para a extração do amido e analisá-lo quanto à composição centesimal, teor de amilose, formato e tamanho de grânulos em microscópio eletrônico de varredura e viscosidade das pastas (RVA). As raizes de P. ahipa apresentaram $18 \%$ de massa seca sendo $7,68 \%$ amido. O rendimento obtido de amido foi baixo $(4,28 \%)$, apontando para a necessidade de estudos que melhorem o processo de extração. O produto obtido apresentou $12,3 \%$ de umidade, $84 \%$ de amido com $13 \%$ de amilose e baixos teores de outros componentes (base úmida). A análise em microscópio eletrônico de varredura mostrou grânulos de amido de formas circular e poligonal, com tamanho variando entre 10 e $25 \mu \mathrm{m}$. O perfil de viscosidade apresentado por este amido mostrou baixa temperatura de pasta $\left(56^{\circ} \mathrm{C}\right)$ e pico de viscosidade a 272 RVU, estando este último valor próximo ao observado para amido de mandioca, sob as mesmas condições. O amido de $P$. ahipa apresentou ainda, baixa estabilidade da pasta a quente e tendência à retrogradação com o resfriamento.

Palavras-chave: raiz; amido; microscopia; viscosidade.
\end{abstract}

\section{SUMMARY}

EXTRACTION AND CHARACTERIZATION OF Pachyrhyzus ahipa STARCH. The species of the genus Pachyrhizus have been studied as a potential starchy raw material source. This work had as purpose the characterization of $P$. ahipa roots and process the roots in laboratory for starch extraction. The centesimal composition and amylose content of starch were analyzed. The starch granule size and shape were observed in scanning electronic microscopy. The Rapid Visco Analyzer was used for viscosity analysis. The P. ahipa roots showed high humidity $(82 \%)$ and $7,68 \%$ of starch. The process yield was low $(4.28 \%)$, which reveal the necessity of searches for improving starch extraction. The product showed $12.3 \%$ of humidity, $84 \%$ of starch (13\% amylose) and low content of other components. The starch granules had circular and polygonal shapes; the size ranged between 10 and $25 \mathrm{~mm}$. The viscosity profile of the $P$. ahipa starch showed low pasting temperature $\left(56^{\circ} \mathrm{C}\right)$, peak at $272 \mathrm{RVU}$, high breakdown value and a tendency to setback.

Keywords: root; starch; microscopy; viscosity.

\section{1 - INTRODUÇÃO}

O Pachyrhizus é um dos poucos gêneros de Fabaceae com raizes comestiveis. O $P$. erosus é a única espécie cultivada em larga escala para o consumo doméstico e exportação, e vem sendo introduzida em várias regiões, inclusive no Brasil. Entretanto, das cinco espécies identificadas do gênero, duas outras são cultivadas: $P$. ahipa e o P. tuberosus, ambas originárias da América do Sul, onde são conhecidas como jacatupé $[5,13]$.

O jacatupé apresenta algumas particularidades bastante interessantes: do ponto de vista da sistemática, devido à ausência de material ancestral primitivo conhecido; do ponto de vista morfológico, devido à presença de genótipos com hábito de crescimento ereto e curto; e, do ponto de vista agronômico, devido à neutralidade de

\footnotetext{
Recebido para publicação em 21/09/2001. Aceito para publicação em 03/04/2003 (000742).

${ }^{2}$ Centro de Raizes e Amidos Tropicais/UNESP - Caixa Postal 237, CEP: 18603-970,Botucatu-SP.E-mail<pesq1cerat@fca.unesp.br>

${ }^{3}$ Departamento de Agroindústria, Alimentos e Nutrição- ESALQ/USP -

Caixa Postal 09, CEP: 13418-900 - Piracicaba-SP. E-mail < sbssarme@ciagri.carpa.usp.br>

${ }^{4}$ Centro de Raizes e Amidos Tropicais/UNESP - Caixa Postal 237, CEP: 18603-970,Botucatu-SP.E-mail <pesq2cerat@fca.unesp.br>

${ }^{5}$ Departamento de Produção Vegetal/Horticultura - FCA/UNESP - Caixa Postal 237, CEP: 18603-970, Botucatu-SP. E-mail <chicocamara@fca.unesp.br>

* A quem a correspondência deve ser enviada.
}

fotoperíodo, curto ciclo de desenvolvimento (5 meses aproximadamente) e sua considerável adaptabilidade climática. Sua distribuição está limitada entre os vales andinos, na Bolivia, até possivelmente o Peru [7].

ORTING et al. [9] analisou 19 introduções de $P$. ahipa e duas de $P$. tuberosus quanto à composição química e encontrou teores de proteína de 8,13 a 20,18\%, açúcares solúveis de 11,37 a 23,94\%, sacarose de 2,91 a 8,44\%, açúcares redutores de 4,06 a 15,51\%, amido de 43,09 a 57\% (expressos na base seca) para Pachyrhizus ahipa.

Com relação ao rendimento, em experimentos de 4 anos conduzidos em Portugal e México, com 7 e 4 meses de ciclo da cultura, respectivamente, foram observados rendimentos em raizes tuberosas frescas da ordem de 29 a 50t/ha, com 19 a 25\% de massa seca [7].

O amido, de modo geral, é utilizado em todos os países e seu consumo aumenta com o grau de desenvolvimento. A situação do setor de amido no mundo pode ser resumida em dois pontos principais: dificilmente novos reagentes químicos ou derivados serão aprovados para uso alimentar e, nos amidos existentes, os niveis permitidos de tratamentos químicos para modificação permanecerão estacionários. As razões para essas restrições são a proteção ao consumidor, segurança de trabalho, proteção ao meio ambiente e economia nos custos de produção [3]. Portanto, as indústrias de alimentos e os produtores agrícolas estão interessados na identificação e no desenvolvimento de espécies que produzam amidos 
nativos, com caracteristicas físico-quimicas especiais. Esses amidos poderiam substituir amidos quimicamente modificados ou abrir novos mercados para amidos [8].

Nesta linha, o objetivo do presente trabalho foi o de processar raizes de Pachyrhizus ahipa, em laboratório, para obtenção de amido, com o intuito de avaliar as características do processo, bem como as do produto obtido.

\section{2 - MATERIAL E MÉTODOS}

\section{1 - Caracterização das raízes}

As plantas de P. ahipa foram cultivadas no Centro de Raizes e Amidos Tropicais- UNESP - Botucatu-SP, a partir de sementes fornecidas originalmente pelo LIEY (Laboratório de Investigaciones Ecológicas de las YungasTucumán - Argentina). O clima em Botucatu de acordo com a classificação Koeppen é definido como Csa ou temperado chuvoso, úmido e com verões quentes, precipitação média anual de $1517 \mathrm{~mm}$ e a temperatura média anual de $20,6^{\circ} \mathrm{C}$. O solo é Latossolo Roxo Destrófico A Moderado. Latitude 22 52'47” S, longitude 48 $25^{\circ} 12^{\prime}$ ” W, altitude $810 \mathrm{~m}$.

As raizes de plantas com 10 meses de idade foram caracterizadas quanto à umidade, cinzas, proteína, matéria graxa, fibras, açúcares solúveis totais [1], açúcares redutores [12] e amido [10]. Foram feitas quatro repetições por análise.

\section{2 - Processamento}

O processamento das raizes foi realizado no laboratório do CERAT/UNESP seguindo as etapas descritas na Figura 1 .

O balanço de massa do processo foi calculado pela relação entre o peso das raízes e do amido produzido, nos estados úmido e seco.

\section{3 - Análises do amido}

$\mathrm{O}$ produto obtido foi caracterizado quanto ao $\mathrm{pH}$, acidez titulável, umidade, cinzas, açúcares totais, fibras, matéria graxa, proteina [1] e amido [10]. O teor de amilose foi determinado segundo a metodologia de WILLIAMS et al. [16]. Foram feitas quatro repetições por análise.

$\mathrm{Na}$ análise do amido em microscópio eletrônico de varredura, as amostras foram diluídas em álcool etilico $100 \%(1 / 10)$ e colocadas duas gotas nos "stubs". Após este procedimento as amostras foram cobertas com $10 \mathrm{~mm}$ de ouro metalizador MED-010 da Balzers e analisadas quanto à forma e ao tamanho dos grânulos em Microscópio Eletrônico de Varredura SEM 515 da Philips, sob tensão de $20 \mathrm{KV}$.

Para a análise da viscosidade foi utilizado o Rapid Visco Analyser (RVA). As suspensões de amido (2,5g amido em $25 \mathrm{~mL}$ de água), corrigidas para a base de $14 \%$ de umidade, passaram pela programação tempo/temperatura: $50^{\circ} \mathrm{C}$ por 1 minuto, aquecimento de 50 a $95^{\circ} \mathrm{C}$ a uma taxa de $6^{\circ} \mathrm{C} / \mathrm{min}$, manutenção da pasta a $95^{\circ} \mathrm{C}$ por 5 minutos e resfriamento de 95 a $50^{\circ} \mathrm{C}$ a uma taxa de $6^{\circ} \mathrm{C} /$ minuto. A viscosidade foi expressa em RVU. Do gráfico obtido foram avaliadas as seguintes caracteristicas: temperatura de empastamento, viscosidade máxima (pico), queda de viscosidade (diferença entre as viscosidades máxima e da pasta mantida a $95^{\circ} \mathrm{C}$ por $5 \mathrm{~min}$.), viscosidade final e tendência à retrogradação (diferença entre as viscosidades final e da pasta a $50^{\circ} \mathrm{C}$ por $5 \mathrm{~min}$.).

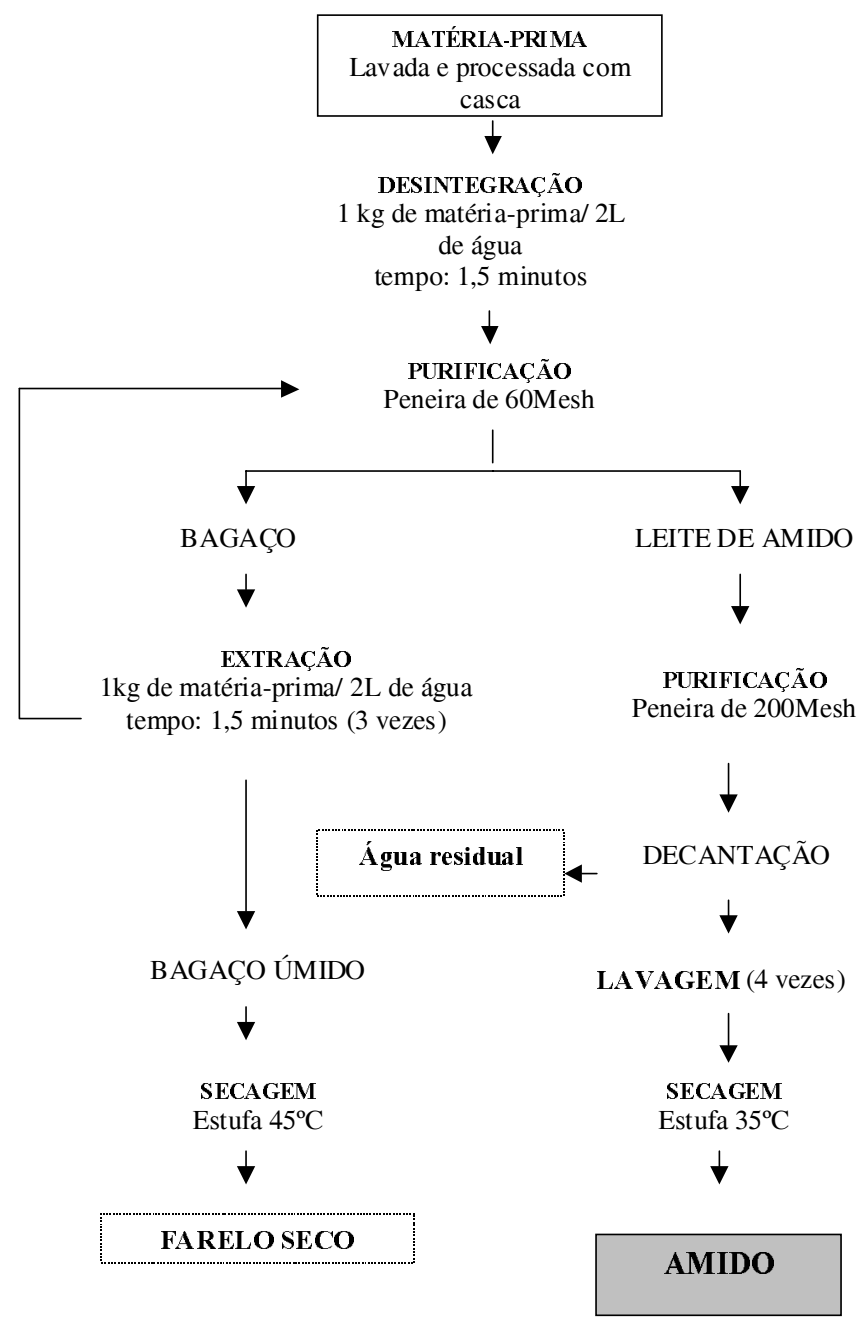

FIGURA 1. Fluxograma do processamento de Pachyrhizus ahipa em laboratório.

\section{3 - RESULTADOS E DISCUSSÃO}

As raizes de $P$. ahipa apresentaram diferentes tamanhos $(10-15 \mathrm{~cm})$, formato alongado, película de cor marrom, grossa, polpa clara e suculenta (Figura 2).

A análise da composição físico-química das raízes (Tabela 1) mostrou elevado teor de umidade, ou seja, baixo teor de matéria seca (18\%), mas com considerável teor de amido e açúcares totais na matéria seca (43\% e 23,5\%, respectivamente). Estes valores foram próximos aos $80 \%$ de umidade e $50 \%$ de amido na matéria seca, observados por ORTING, GRUNEBERG \& SORENSEN [9]. 


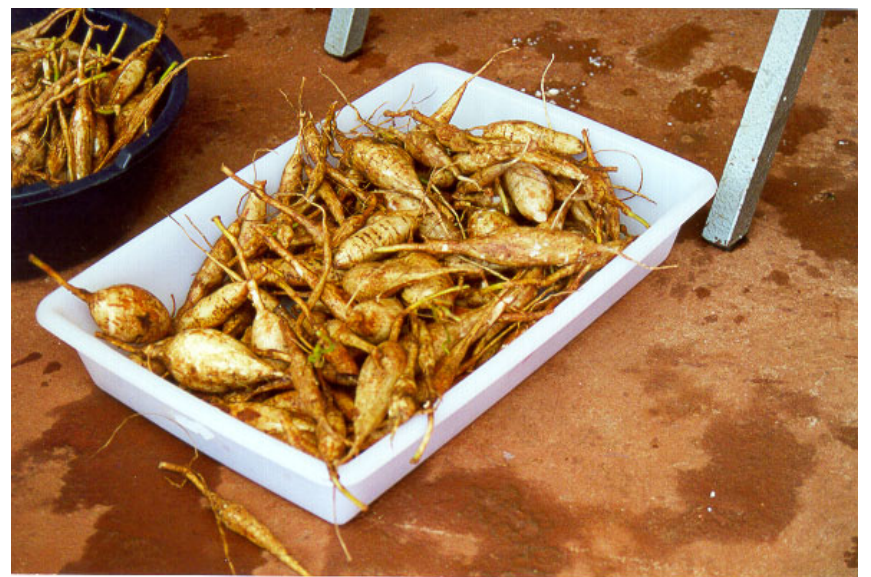

FIGURA 2. Raízes de Pachyrhizus ahipa.

TABELA 1. Composição fĩsico-química das raízes de P. ahipa.

\begin{tabular}{lc}
\hline Análises & Média \\
\hline$\%$ base úmida & \\
Umidade & $82,00 \pm 0,67$ \\
Amido & $7,68 \pm 0,46$ \\
Cinzas & $0,40 \pm 0,03$ \\
Matéria graxa & $0,10 \pm 0,01$ \\
Proteína & $1,00 \pm 0,04$ \\
Fibras & $0,74 \pm 0,05$ \\
Açúcares redutores & $2,68 \pm 0,07$ \\
Açúcares totais & $4,24 \pm 0,20$ \\
pH & $5,52 \pm 0,05$ \\
Acidez titulável $(\mathrm{mL} \mathrm{NaOH} 1 \mathrm{~N})$ & $1,04 \pm 0,09$
\end{tabular}

No processamento para extração do amido optouse pelo não descascamento; contudo, foi observado que a moagem em liquidificador não foi eficiente, ficando um resíduo bastante fibroso. O rendimento do processo em relação à matéria fresca inicial foi baixo $(4,28 \%)$. Avaliando-se a porcentagem de amido extraido, verifica-se que esta também pode ser considerada baixa $(38,04 \%)$, indicando a necessidade de ajustes neste processamento (Tabela 2).

TABELA 2. Balanço de massa do processamento.

\begin{tabular}{lc}
\hline Variáveis & Resultados \\
\hline Peso da matéria-prima processamento & $5,7 \mathrm{Kg}$ \\
Umidade das raízes & $82,00 \%$ \\
Matéria seca inicial & $1,03 \mathrm{Kg}$ \\
Amido na matéria seca & $442,9 \mathrm{~g}$ \\
Peso do resíduo úmido & $2,22 \mathrm{Kg}$ \\
Umidade do resíduo & $82,88 \%$ \\
Matéria seca no resíduo & $380,06 \mathrm{~g}$ \\
Peso da fécula & $244,22 \mathrm{~g}$ \\
$\%$ de amido na fécula & $83,71 \%$ \\
Peso em amido & $204,44 \mathrm{~g}$ \\
Amido extraído & $46,15 \%$ \\
Rendimento prático da extração & $\mathbf{4 , 2 8 \%}$ \\
\hline
\end{tabular}

Os resultados das análises do amido (Tabela 3) mostram que o produto está de acordo com os limites esta- belecidos pela Legislação Brasileira para amidos comerciais que são: $14 \%$ de umidade, mínimo de $80 \%$ de amido, máximo de $0,5 \%$ de cinzas e acidez máxima (\%p/p) de $1,00 \mathrm{~mL}$ de $\mathrm{NaOH} \mathrm{N} / 100 \mathrm{~g}$ [2]. Entretanto, o teor de fibras foi elevado indicando a necessidade de melhor purificação do leite de amido. Segundo VILPOUX \& CEREDA [15], são aceitáveis teores abaixo de 0,59\%, já que altos teores de fibras podem restringir usos.

Quanto ao teor de amilose, a porcentagem observada foi próxima aos teores citados por FORSTHY et al. [6], que avaliando seis introduções de $P$. ahipa observaram uma variação no teor de amilose de 11,6 a 16,8\%.

TABELA 3. Composição fĩsico-química do amido.

\begin{tabular}{lc}
\hline Análises & Média \\
\hline \% base úmida & \\
Umidade & $12,31 \pm 0,01$ \\
Amido & $83,71 \pm 0,36$ \\
Cinzas & $0,28 \pm 0,01$ \\
Matéria graxa & $0,41 \pm 0,04$ \\
Proteína & $0,10 \pm 0,01$ \\
Fibras & $1,69 \pm 0,05$ \\
Açúcares totais & $0,30 \pm 0,01$ \\
Amilose $(\%)$ & $12,84 \pm 0,56$ \\
pH & $6,45 \pm 0,04$ \\
Acidez titulável $(\mathrm{mL} \mathrm{NaOH} 1 \mathrm{~N} / 100 \mathrm{~g})$ & $0,64 \pm 0,04$ \\
\hline
\end{tabular}

A observação do amido em microscopia eletrônica de varredura permitiu a observação de que os grânulos de amido de Pachyrhizus ahipa apresentam as formas circulares e poliédricas, com tamanho (diâmetro maior) variando de 10 a $25 \mu \mathrm{m}$ (Figura 3).

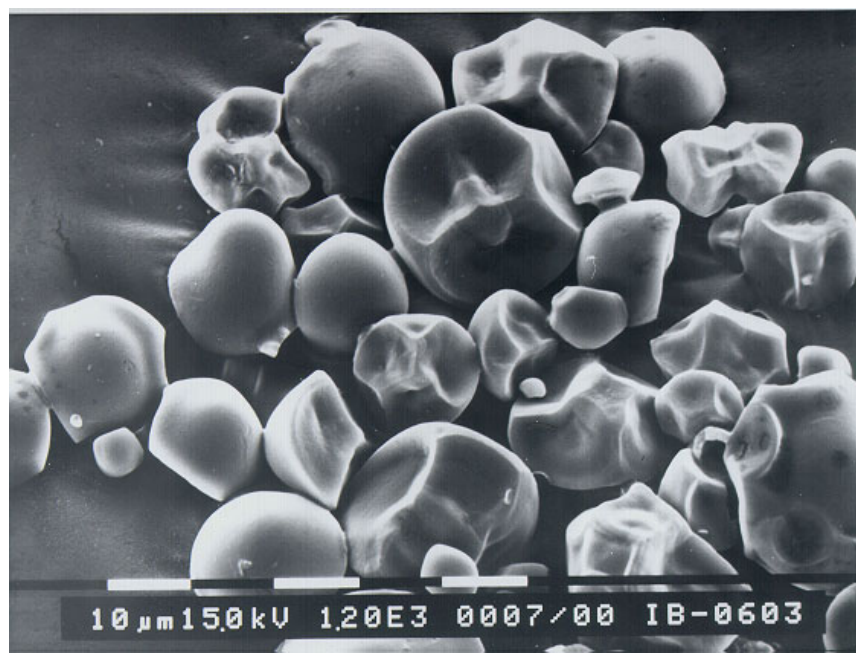

FIGURA 3. Micrografia de grânulos de amido de $P$. ahipa observados em microscópio eletrônico de varredura (aumento de 1440x).

BERMUDEZ [4], caracterizando amidos de diferentes fontes botânicas, cita a forma poliédrica como característica dos grânulos de amido de $P$. erosus, e os tamanhos de $6 \mu \mathrm{m}$ de diâmetro menor e $8 \mu \mathrm{m}$ de diâmetro maior. Portanto, não foram observadas diferenças en- 
tre as formas nas diferentes espécies, mas o tamanho dos grânulos foi maior nas raizes de $P$. ahipa.

A viscosidade aparente do amido de $P$. ahipa avaliada pelo Rapid Visco Analyser pode ser observada pela Figura 4. O amido de P. ahipa apresentou temperatura de pasta de $56,0^{\circ} \mathrm{C}$, inferior àquelas encontradas por TAKIZAWA et al. [14] em amidos convencionais de tuberosas como a batata $(64,8 \%)$ e a mandioca $(66,7 \%)$. Baixas temperaturas de pasta evidenciam menor grau de associação nas zonas amorfas dos grânulos de acordo com ROSENTHAL et al. [11].

O perfil de viscosidade do amido de P. ahipa (Figura 4) apresentou pico de $272 \mathrm{RVU}$, valor semelhante aquele observado para amido de mandioca, que foi $248 \mathrm{RVU}$ [14], nas mesmas condições. A queda acentuada de viscosidade (163 RVU) observada após o pico é caracteristica de pastas com baixa estabilidade a quente, cujos grânulos se rompem sob agitação mecânica. Após a quebra de viscosidade, com o resfriamento, foi observada tendência a retrogradação de 65 RVU, atingindo a uma viscosidade final de 173 RVU.

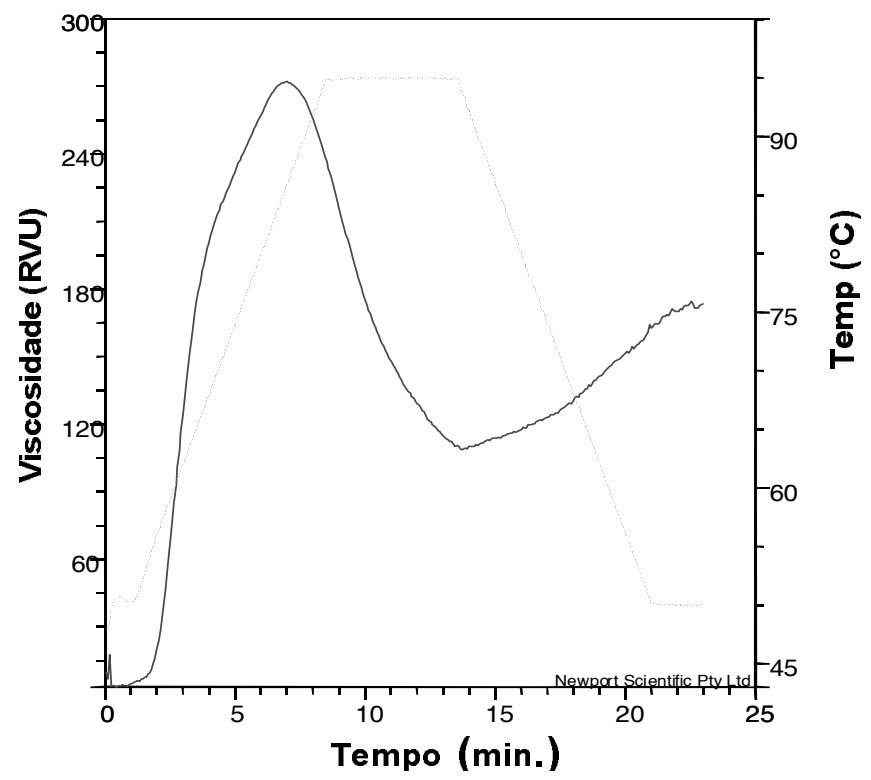

FIGURA 4. Propriedades de pasta do amido de $P$. ahipa $(2,5 \mathrm{~g} /$ $25 \mathrm{~mL}$ ) em Rapid Visco Analyser.

\section{4 - CONCLUSÕES}

A partir dos resultados obtidos foi possivel concluir que $P$. ahipa apresenta potencial de uso como matéria prima para as indústrias de amido, principalmente pelas características apresentadas em sua composição química (considerável teor de amido com baixo teor de amilose), tamanho mediano de grânulos e prorpiedades viscográficas com baixa temperatura de pasta, instabilidade da pasta sob agitação em temperatura elevada e tendência à retrogradação, caracteristicas estas de interesse para diferentes aplicações. Contudo, faz-se necessários ajustes no processamento para obtenção de melhores rendimentos em amido.

\section{5 - REFERÊNCIAS BIBLIOGRÁFICAS}

[1] ASSOCIATION OF OFFICIAL ANALYTICAL CHEMISTS. Official methods of analysis. 13. ed. Washington, 1980. 109p.

[2] BRASIL. Leis, decretos, etc. Decreto n. 12.486 de 20 de outubro de 1978. Normas técnicas especiais relativas a alimentos e bebidas. Diário Oficial do Estado de São Paulo, 21 out., 1978. p. 20.

[3] BE MILLER, J.N. Starch modification: changes and prospects. Starch/Stärke, v. 49, n. 4, p. 127-131, 1997.

[4] BERMUDEZ, J.N. Valorización de las amiláceas "nocereales" cultivadas en los países andinos: estudio de las propriedades fisicoquimicas y funcionales de sus almidones y la resistencia a diferentes tratamientos estressantes. Bogotá, 1997. 150p. Trabajo de Grado (Faculdad de Ingenieria de Alimentos) - Universidad de Bogotá.

[5] CASTELlanos, J.Z., ZAPATA, F., RADILlo, V., PEÑACABRIALES, E., JENSEN, S., HEREDIA-GARCIA, E. Symbiotic nitrogen fixation and yield of Pachyrhizus erosus (L) urban cultivars and Pachyrhizus ahipa (Wedd) parody landraces as affected by flower pruning. Soil Biol. Biochem.,v. 29, n. 5/6, p. 973-981, 1997.

[6] FORSTHY, J. L., RING, S. G., NOEL, T. R., PARKOS, R., FINSLAY, K., SHEWEY, P. R. Characterization of starch from tubers of yan bean (Pachyrhizus ahipa). J. Agric. Food Chem. v. 50, p. 361-367, 2002.

[7] HERMANN, M., HELLER, J. Andean roots and tubers: Ahipa, arracacha, maca and yacon. Promoting the conservation and use of the underutilized and neglected crops. Rome, v. 1, 1997.

[8] KIM, Y.S., WIESENBORN, D.P. , ORR, P. H., GRANT, L.A. Screening potato starch for novel properties using differential scanning calorimetry. Journal of Food Science, v. 60, n. 5, p. 1060-1065, 1995.

[9] ORTING, B., GRÜNEBERG, W.J., SORENSEN, M. Ahipa (Pachyrhizus ahipa (Wedd.) Parodi) in Bolivia. Genet. Resour. Crop Evolution, v. 43, p. 435-446, 1996.

[10] RICKARD, J. E., BEHN, K. R. Evaluation of acid and enzyme hydrolytic methods for determination of cassava starch. J. Sci. Food Agric., v. 41, n. 4, p. 373 - 9, 1987.

[11] ROSENTHAL, F.R.T., MELLO, A.P. ; PELEGRINO, S.L.; NAKAMURA, T. Amido de mandioca. 2. Estudo de estrutura em variedades de Minas Gerais. Rev. Bras. Tecn. , v. 4, p. 7-17, 1973.

[12] SOMOGY, M. Determination of blood sugar. J. Biol. Chem., v. 160, p. $69-73,1945$.

[13] SOREnSEn, M., GRÜNEBERG, W., ORTING, B. Ahipa. Pachyrhizus ahipa (Wedd.) Parodi. In: HERMANN, M., HELLER, J. (Ed.) Andean roots and tubers: Ahipa, arracacha, maca and yacon. Promoting the conservation and use of the underutilized and neglected crops. Rome: International Plant Genetic Resource Institute, cap 2, p. 75-172, 1997.

[14] TAKIZAWA, F.F., SILVA, G.O., PEDROSO, R.A., SARMENTO, S.B.S., DEMIATE, I.M. Análise viscoamilográfica de amidos tropicais modificados por tratamentos oxidativos. In: ENCONTRO REGIONAL SUL DE CIÊNCIA E TECNOLOGIA DE ALIMENTOS, 7., Curitiba, 2001. Anais. Curitiba: SBCTA/PPGTA/UFPR, 2001. p. AMA4-01.

[15] VILPOUX, O., CEREDA, M. P. Caracterização das fecularias no Brasil. Botucatu: Centro de Raízes Tropicais, UNESP, 1995. 58p.

[16] WILLIAMS, P. C., KUZINA, F.D., HLYNKA, I. A rapid colorimetric method for estimating the amylose content of starches and flours. Cereal Chemistry, v. 47, n. 4, 1970. 